\title{
Contract Workers in Japan's Nuclear Utility Industry: Can We Maintain Safety and Health Standards at Nuclear Power Plants?
}

\author{
Akikuni Matsumoto ${ }^{1}$, Hisayuki Hara ${ }^{2}$ and Kazumitsu Nawata ${ }^{1{ }^{*}}$ \\ ${ }^{1}$ Department of Technology Management for Innovation, University of Tokyo, 7-3-1 Hongo, Bunkyo-ku, Tokyo \\ 113-8656, Japan \\ ${ }^{2}$ Faculty of Economics, Niigata University, 8050 Ikarashi 2-no-cho, Nishi-ku, Niigata 950-2181, Japan
}

\begin{abstract}
Many small contracting firms are used to maintain nuclear power plants in Japan. The accident at the Fukushima nuclear plant raised the serious question as to whether safety standards can be upheld with this system. A review of regulations governing Japan's nuclear utility industry derived two imperfect information models that implied opposing incentives for utility companies to use contract workers rather than hire employees. We then analyzed the dataset of nuclear plant worker's exposure to radiation in the power generation industry. The results suggest that using contract workers enables the utility companies to implement lower standards than those imposed by regulations and to reduce costs by circumventing responsibilities legally imposed on employers.
\end{abstract}

Keywords: Nuclear power plant, Risk management, Contract worker, Safety and health education.

\section{INTRODUCTION}

On March 11, 2011 an earthquake and tsunami caused one of world's worst nuclear accidents at the Fukushima Daiichi nuclear power station of the Tokyo Electric Power Company (TEPCO). It had been believed that Japan's nuclear utility industry could safely withstand such natural disasters. After the accident, the question of whether nuclear plants were prepared for future disasters became a critical and controversial issue. Therefore, this study examines the relationship between occupational risks and types of employment at Japan's nuclear power plants.

The practice of replacing permanent employees with temporary workers has been spreading throughout all major industries in developed countries. Thus, employees of contracting firms who are doing their jobs on sites specified by the host plant (hereafter, contract workers) are becoming more important. These workers are similar to temporary agency workers, but with the important difference that contract workers include many permanent employees. With the demand for contract workers increasing, differences in the working conditions of these workers and the host company's employees have become important subjects of study, because these differences might compromise the safety conditions on industrial sites. In the United States, safety and health education and training (hereafter, safety training) of contract workers attracted attention following the 1989 Phillips Petroleum

*Address correspondence to this author at the Department of Technology Management for Innovation, University of Tokyo, 7-3-1 Hongo, Bunkyo-ku, Tokyo 113-8656, Japan; Tel: +81-3-5841-8756; Fax: +81-3-3818-7492;

E-mail: nawata@tmi.t.u-tokyo.ac.jp explosion at a chemical plant in Pasadena, Texas, that killed 23 people and injured 300 . Because the plant engaged contract workers, the safety conditions of workplaces that depend on such workers became a major issue. The U.S. Occupational Safety and Health Administration (OSHA) hired the John Gray Institute to collect data about safety issues in the U.S. petrochemical industry. Wells et al. (1991) were project members, and reported the results of the investigation. Their report involved surveys of plant managers, employees, and contract workers, as well asnine plantlevel case studies. Kochan et al. (1992) provided a summary of the report. Data from surveys of plant managers and case studies were not available from OSHA.

Wells et al. (1991) found that contract workers and employees differed in education, age, ability to speak and understand spoken English, and other attributes. In the U.S., host plants may order and supervise contract workers, and responsibility for accidents is determined based on whether the host plant is regarded as a coemployer. Wells et al. (1991) reported three reasons why companies prefer to use contract workers: it reduces compensation costs, ensures workforce flexibility, and provides workers with specialized skills. They also mentioned avoiding co-employment as a controversial motivation. Rebitzer (1995) conducted a deep analysis using the same data, and found that host plants have an incentive to pass responsibility for safety training and supervision of contract workers to the contracting firms that provide the workers. By doing so, the host plants can escape from potential liabilities and avoid becoming co-employers. On the basis of probit analyses of accident rates, he also found that 
host plants offered more effective safety training and supervision for both contract workers and employees than contracting firms. Only a few studies have been done to analyze the differences in accidents and occupational injuries between contract workers and employees. However, there are studies about the effects of length of employment, and most of them have found that type of employment contract had little influence if factors such as job descriptions and working conditions are controlled for (AmuedoDorantes, 2002; Guadalupe, 2003; Hernanz and Toharia, 2006). These studies focused on whether accidents or occupational injury rates depended on type of employment, and their results suggested that both were affected by safety training.

In this paper, we first present theoretical explanations for differences in safety levels between contract workers and employees, using data on Japan's nuclear power industry. There were 54 commercial nuclear power plants (hereafter, nuclear plants) in Japan as of March 2010. In nuclear plants, contract workers are used mainly to perform periodic inspections. Each reactor facility must be inspected within 13 months of its previous inspection. Inspection data from 1998 to 2004 for the seven plants at the Kashiwazaki-Kariwa Nuclear Power Station of the TEPCO indicated that periodic inspections took 198 days, on average. There are typically multiple reactor facilities in one plant, and therefore, the percentage of contract workers has been constantly high.

Numbers of employees at each nuclear plant are recorded annually in the Operational Status of Nuclear Facilities in Japan by the Japan Nuclear Energy Safety Organization. In 2009, 9,210 utility company-employed workers (hereafter, utility employees) were potentially exposed to radiation at their job site. On the other hand, 74,279 contract workers were potentially exposed to radiation at those same facilities. The latter number is eight times larger than the former. Moreover, we found that radiation exposure levels were much higher for contract workers than for utility employees. About 0.58 and 0.02 percent of utility employees were exposed to radiation exceeding $5 \mathrm{mSv}$ (millisievert) and $10 \mathrm{mSv}$, respectively. Meanwhile, these numbers jumped to 4.6 and 1.44 percent for contract workers. The effects of type of worker were significant.

In 2002, Junichiro Koizumi, the prime minister of Japan, admitted that three fatal cases of occupational injury and illness (hereafter, occupational injury) had been certified in nuclear plants as resulting from radiation-related diseases. All three fatalities were contract workers according to their job titles. Using worker data that describes contract workers and utility employees separately, we show that Japan's nuclear utility companies prefer to use contract workers. This practice could prevent plants from achieving proper occupational safety and health standards, and it could potentially increase societal costs.

The remainder of this paper is organized as follows. Section 2 presents a brief history and the current components involved in the regulation of contract workers in Japan's nuclear utility industry. Section 3 shows how these regulations lead to several implications in conventional imperfect information models. Section 4 presents an empirical study that examines hypotheses about the obtained implications. Section 5 concludes the paper.

\section{CONTRACT WORKERS AND REGULATION OF JAPAN'S NUCLEAR UTILITY INDUSTRY}

This section describes the present situation and history of Japanese regulations relating to contract workers and the nuclear utility industry based on Sugeno (1992), Hamaguchi (2004), and Anayama (2005).

\subsection{Regulations Relating to Contract Workers}

Using contract workers is considered a normal activity, and therefore no formal laws directly regulate their employment, although conditions are placed on their use. Since employing contract workers is similar to employing temporary agency workers, their contracts are indirectly regulated under the Employment Security Act and the Worker Dispatching Act. ${ }^{1}$ The Employment Security Act was enacted in 1947 under the influence of the International Labor Organization (ILO) convention and recommendations $\mathrm{C} 034$ and R042 of 1933. Until 1985, it prohibited commercial employment agencies and labor supply agencies, other than free employment agencies managed by labor unions. This law was intended to eliminate "bosses" who acted as labor supply agencies and human traffickers; it protected workers against human rights infringements. The term "labor supply" formerly referred to employing people who worked under the direction of others

\footnotetext{
${ }^{1}$ The Act for Securing the Proper Operation of Worker Dispatching Undertakings and Improved Working Conditions for Dispatched Workers is commonly known as the Worker Dispatching Act. We use the latter term in this paper.
} 
according to a supply contract. Thus, the temporary agency was regarded as an example of the labor supply agency. This regulation was based on the consideration that forced labor and intermediary exploitation were more likely if the host could directly control the working conditions of contract workers.

Immediately after the Employment Security Act took effect, exceptions were made to its enforcement. Ministerial ordinances were instituted for industries that were deemed unable to operate because of the law, and at which it was deemed that human rights infringements were not a concern. ${ }^{2}$ For example, the occupations of nurse and midwife were such exceptions. The Worker Dispatching Act enacted in 1985 was originally a prohibition-based law that permitted dispatching of workers only for explicitly identified types of jobs. ${ }^{3}$ Between 1994 and 2003, however, worker dispatching was drastically deregulated, and with few exceptions, it remains unregulated. The Employment Security Act was amended in 1985. Under the present law, labor supply refers to "having workers work under the direction and orders of another person based upon a supply contract, and does not include that which falls under worker dispatch provided in Article 2, item 1 of [the Worker Dispatching Act]" (Article 4, paragraph 6 of the Employment Security Act). ${ }^{4}$ That is, the law was changed to acknowledge the contractual relationship among suppliers, host, and workers on the understanding that the relationship would not lead to the infringements of workers' rights. Currently, such a relationship is called a temporary agency or worker dispatching business. Most European labor markets were also deregulated around these years. ${ }^{5}$

Shirai (2007) compared several surveys of Japanese manufacturing and found the use of contract workers expanded rapidly in the 1990s alongside deregulation of the worker dispatching business. Onsite contracting firms and temporary agencies are similar in that both supply labor to other industries as a business. Contract workers have been common in the

\footnotetext{
${ }^{2} \mathrm{~A}$ ministerial ordinance is an order issued by the relevant ministry under the relevant law.

${ }^{3}$ Hamaguchi (2004) argued that the regulations imposed on employment agencies were not concerned with protecting human rights, but rather, with protecting the employees of the host plant.

${ }^{4}$ We referred to the following website for translated statements of Japanese Laws: http://www.japaneselawtranslation.go.jp.

${ }^{5}$ The OECD Indicator of Employment Protection of 1985-2008. In 1997, the ILO adopted convention $\mathrm{C} 181$ and recommendation $\mathrm{R} 188$ to recognize employment agencies and temporary agencies as legitimate bodies of the labor market.
}

construction industry. In 1970, the Safety and Health Subcommittee of the Ministry of Labour was established to address safety and health problems among contract workers. Its 1971 report pointed out that the then-current methods of correcting problems among small- and medium-sized firms and on-site contracting firms were inadequate (Hamaguchi, 2004:236). It was widely known that the use of contract workers could generate problems of occupational safety and health management by making contract work hierarchical; however, the regulations primarily targeted direct employment contracts (Figure 1). ${ }^{6}$ The Industrial Safety and Health Act was enacted in 1972 on the basis of this report. According to this act, the senior contracting firm in the hierarchy is responsible for the safety and health of all contract workers, including those in the lower tiers of the hierarchy. Therefore, host plants are not responsible for the safety and health of contract workers. In contrast, the Worker Dispatching Act makes the host plant, as well as the temporary agency, responsible for the safety and health of temporary agency workers (Article 45 of the Worker Dispatching Act).

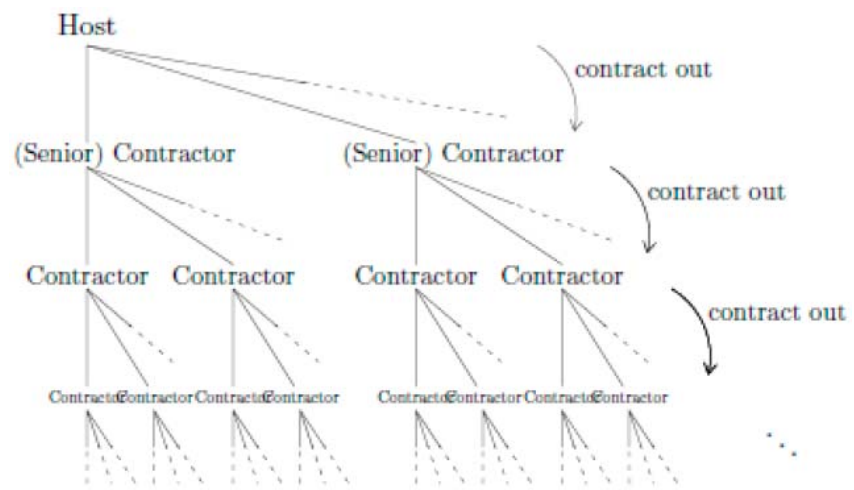

Figure 1: Hierarchical use of contracting firms.

In Public Notice No. 37 of 1986, the Ministry of Health, Labour and Welfare distinguished between worker dispatching and on-site contract work. ${ }^{7}$ Figure 2 shows how relationships work within each. ${ }^{8}$ Temporary agencies employ workers, and the host supervises and issues orders to dispatched workers. In contrast, the host hires the contracting firm, which in turn hires and

\footnotetext{
${ }^{6}$ On the basis of data supplied by TEPCO, Shimizu (2002) revealed that TEPCO recognized as many as five strata of contracting firms from the top contracting firms in the Fukushima Daiichi nuclear power station as of December 1, 2001. The average number of employees per contracting firm was less than five in the fourth and fifth strata.

${ }^{7}$ The public notice is an instruction issued by the relevant ministry under the relevant law and order.

${ }^{8}$ Available at http://www.mhlw.go.jp/bunya/koyou/dl/tekisei.pdf (accessed May 1, 2014) (in Japanese).
} 


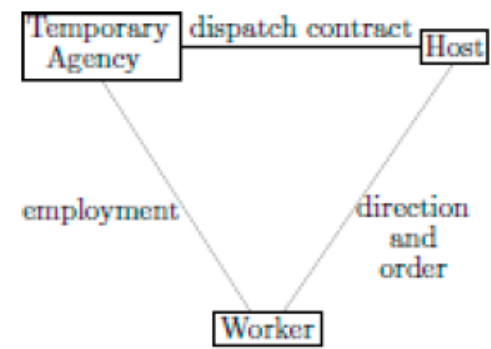

(a) Worker dispatch

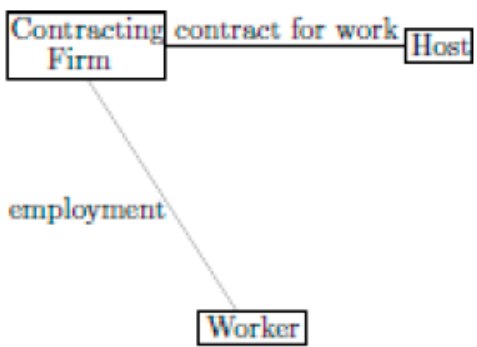

(b) Contract for work

Figure 2: Relationships with workers in worker dispatch and on-site contract work.

issues order to contract workers. In other words, contract workers are not under the direct control of the host plant. However, distinguishing a temporary agency business from a contract-for-work situation is seldom easy. The Prefectural Labour Office investigates whether the relationship among suppliers, hosts and workers is that of contract-for-work and makes recommendations, if necessary. If contract specifications are extremely lax, all substitutable workers might be regarded as self-employed persons engaged in contract works with their actual employers. If contract specifications are extremely strict, companies would have to hire engineers even to repair a water pipe.

Previous studies on transaction costs usually focused on the benefits of integrating the two types of workers (e.g., Williamson [1971], Klein et al. [1978], Grossman and Hart [1986]). However, the benefits of outsourcing are focused on the contract-for-work context. Generally, three incentives induce companies to hire contract workers (see, e.g., Abraham and Taylor [1996]):

1. The employees' wage rate is higher than that of external workers. ${ }^{9}$ This fact is explained by the efficiency wage hypothesis that companies pay employees above-market wages to control employees' efficiency.

2. The cost of adjusting labor inputs is less for contract workers than for employees. Generally, companies incur costs for increasing or reducing their own workforce. However, host companies can simply reduce contract workers as part of cost reductions. It is also easy for contracting firms to justify reducing the number of their

\footnotetext{
${ }^{9}$ Garen (2006) also discussed fringe benefits.
}

employees when they face financial difficulties caused by a decrease in demand. ${ }^{10}$

3. The more a company faces the demand, the more it can enjoy economies of scale if the task requires some investment in special skills, equipment, or facilities. A company can benefit from outsourcing to a firm that faces more demand and hence has more economies of scale. Since a nuclear plant requires special equipment and skills for its reactor, outsourcing the tasks of inspection and maintenance to manufacturers may be preferable.

However, a large proportion of the contracting firms that constitute the contracting firm hierarchy are very small firms compared to the utility companies, which are some of the largest firms in Japan. It is questionable whether such small firms have more economies of scale than the utility companies. Furthermore, maintenance activities are constantly underway in nuclear plants, since nuclear plants usually have multiple reactors. Outsourcing may offer relatively few benefits, and hiring employees for such jobs might be preferable.

In addition to these motivations, Shirai (2007) and Wells et al. (1991) pointed out that companies can circumvent an employer's legal responsibilities by hiring contracting firms. ${ }^{11}$ For a dispatched worker, the host assumes some employer responsibilities - for example, occupational safety training. In addition, in principle, the Worker Dispatching Act prohibits hosts from engaging worker dispatching services continuously for more than three years (Article 40-2, paragraph 3; and Article 40-5). No such restriction

\footnotetext{
${ }^{10}$ Employers need to satisfy rigid conditions for dismissal based on legal precedents in Japan, particularly if the dismissal is owing to economic circumstances. For details, see Sugeno (1992, pp. 407-410).

${ }^{11}$ Wells et al. (1991) also pointed out that the use of contract workers results in union avoidance.
} 
pertains to contract workers, and contracting firms bear all obligations for assuring that contract workers obey relevant laws. This fact is inseparable from regulation that prohibits host companies from ordering contract workers.

\subsection{Laws Regulating Japan's Nuclear Utility Industry}

Japan's nuclear utility industry is regulated under the Electricity Business Act and the Act on the Regulation of Nuclear Source Material, Nuclear Fuel Material and Reactors. In general, the former stipulates conditions about facilities and equipment, and the latter regulates management of compliance and safety training to enhance public safety by preventing radiation-related hazards. An important ministerial ordinance under the latter law-the Rule for the Installation, Operation, etc. of Commercial Nuclear Power Reactors-requires nuclear plant operators or utility companies to provide operational safety programs (Articles 7 and 16) and report accidents and irregularities (Article 19-17). Article 7-5 of this ordinance also requires utility companies to assess their activities, incorporate lessons from the experiences of other utility companies in their own practices, and undergo inspections to assure that they comply with regulations. These requirements increase risk-management costs. If violations of safety protocols occur, utility companies may be ordered to suspend reactor operations (Article 33 of the Act on the Regulation of Nuclear Source Material, Nuclear Fuel Material and Reactors and Article 98 of the Industrial Safety and Health Act).

Uezu et al. (2007) determined that occupational injury rates that include injuries to contract workers are higher than rates that count only injuries to employees. According to the Ministry of Health, Labour and Welfare (2005), the smaller the firm, the smaller the fraction of workers offered safety training during orientation. Moreover, the report on the accident at the Mihama Nuclear Power Station (operated by Kansai Electric Power Company) on August 9, 2004 pointed out that employees (not contract workers) should have checked and maintained the thickness of the pipe in the secondary loop to assure safety. This fact suggests the utility company recognized that employees were preferable for jobs requiring extensive safety training.

When a severe nuclear accident occurs, the utility company is assigned sole liability. The Act on Compensation for Nuclear Damage holds operators of nuclear facilities strictly responsible for nuclear damage caused by factors other than disasters, upheavals, and similar incidents (Article 3). The law is intended to protect accident victims and promote business by reducing the risk of contracting firms. It also specifies that contracting firms are not liable for unintentional nuclear damage caused by reactor operation (Articles 4 and 5). Contracting firms are not liable for their faults, errors or mistakes if they are not intentional. In short, contracting firms are perfectly protected by limited liability, and all the utility company can do is to terminate a contract if an accident takes place. The host company cannot audit contract workers in this case, because direct supervision of contract workers by the host is prohibited. ${ }^{12}$ This fact seems to make the information rent higher than required to offset the technical advantage of the contracting firm if it even exists.

\section{MODEL FEATURING IMPERFECT CONTRACTING FIRM INFORMATION}

We first present potential problems regarding level of safety training when contracting firms are used under the condition of imperfect and asymmetric contract information. Then we consider two models that explain why a utility company would use contracting firms for jobs that pose a risk of accidents.

\subsection{Potential Problems Under the Imperfect and Asymmetric Contract Information}

In the relationship between the utility company and the contracting firm involving asymmetric information, the former may be unable to offer a contract such that the latter voluntarily chooses an appropriate level of safety training. Verifying training is often too costly, since direct supervision by the host is not allowed and a large number of contracting firms form hierarchies. Furthermore, the utility company may prefer not to offer a contract that leads to appropriate training levels if the socially optimal level required by the regulator exceeds the privately optimal level. In this case, the utility company offers the contracting firm fees that do not reflect the cost of conducting the necessary safety training.

For simplicity, let us consider a case in which a utility company does not use contract workers and only

\footnotetext{
${ }^{12}$ Article 16 of the Act on Compensation for Nuclear Damage also provides that the government can subsidize the part of the compensation that exceeds the stipulated amount.
} 
one type of accident is possible. Let $T$ and $N$ be the utility company's strategies corresponding to whether it offers safety training. Expected profits for Strategies $T$ and $N$ are written as

$$
\begin{aligned}
& \Pi^{T}=R-P^{T} L-C \text { and } \\
& \Pi^{N}=R-P^{N} L
\end{aligned}
$$

respectively. $R$ is the revenue, $P$ is the accident probability, $L$ is the loss from an accident, and $C$ is the cost of safety training. The utility company chooses Strategy $T$ when $\Pi^{T} \geq \Pi^{N}$; or, in other terms, $\left(P^{N}-P^{T}\right) L-C \geq 0$. Strategy $N$ becomes optimal when the effect of safety training, $\left(P^{N}-P^{T}\right)$, is small; the loss by accident, $L$, is small; and the cost of safety training, $C$, is large.

Even if the occupational safety training effectively reduces the probability of an accident, severe accidents are rare, and the likelihood decreases as severity increases. Periodic inspections stop a reactor for about 198 days every 13 months. Compared to the cost of periodic inspections, the cost of human errors and loss by accident, are likely to have no major impact on the operations of nuclear plants. Therefore, we may conclude that $\left(P^{N}-P^{T}\right)$, and $L$ may be ignored in the utility company's decision.

This can also be explained as follows. Where the regulator and the utility company are the principal and agent, respectively, the former can motivate the latter to assure a level of worker safety training by penalizing it for inadequate training. However, informational asymmetry occurs when the utility company engages contracting firms and requires them to train contract workers appropriately. The number of contracting firms far exceeds the number of utility companies: only ten companies have nuclear plants, whereas there are thousands of contracting firms. It is difficult for the regulator to inspect that many firms, and thus, to verify appropriate safety training.

\subsection{A Model with Economies of Scale as Motivation for the Use of Contracting Firms}

Here, we present a model of moral hazard (Laffont and Martimort, 2002; Bolton and Dewatripont, 2005), assuming the utility company wants to restrict the probability of accidents and has imperfect information about the contracting firms' safety training. Note that a framework of adverse selection (Rothschild and Stiglitz, 1976) also derives similar results.
We consider four assumptions:

1. The utility company's revenue decreases if an accident occurs.

2. The probability of an accident decreases as workers' safety training increases.

3. The safety training cost is positive.

4. The utility company decides whether to hire contracting firms by comparing the maximum expected profits.

It is reasonable to assume that the probability of an accident rises as the degree of workers' safety training decreases, because training to prevent occupational injuries is related to training for the prevention of severe accidents. If workers are insufficiently trained about operational risks, they are more likely to adopt shortcuts to reduce their work burden. For instance, two workers were killed by a critical accident in 1999 at the uranium processing plant in Tokai-mura in Japan because they violated operating procedures for their own convenience.

In models involving asymmetric information, the principal must pay an information rent to the agent to control accident risk. The present value of the total expected profit of the utility company that does not hire contracting firms is written as

$\Pi^{N}=R-P(C) L-C$

where the superscript $N$ indicates "without contracting firms." We assume that $P^{\prime}<0$, and $P$ " $>0$. The first order condition is written as

$\frac{d}{d C} P\left(C^{*}\right)=-\frac{1}{L}$

The present value of the total expected profit of the utility company that hires contracting firms $\Pi^{C}$, as well as that of the contracting firms $\pi$ are written as

$$
\Pi^{C}=R-P^{C}(F) L-\left(1-P^{C}(F)\right) F \text { and }
$$

$\pi=(1-p(c)) F-c$

where superscript $C$ indicates "with contracting firms," $F$ is the present value of the total contracting firm fee transferred from the utility company to the contracting firms, $p$ is the accident probability, $P^{C}$. is the accident probability that the utility company estimates, and $c$ is 
the safety training cost. We assume that $p^{\prime}<0$, and $p ">0$. For simplicity, let us assume that the utility company knows $c$ and the shape of $p$. We also assume that $p(c)=P(c+a)$ where a positive value for $a$ indicates the contracting firm's technical advantage in the occupational safety field, or economies of scale.

If the utility company can verify the contracting firm's effort $c$ (first best case), the optimization problem is written as

$$
\max _{c, F} \Pi^{C}=R-P(c+a) L-(1-P(c+a)) F
$$

$$
\text { s.t. } \pi \geq 0 \text { (participation condition). }
$$

Then, from the first order condition, the host's problem is equivalent to

$$
\max _{c} \Pi^{C}=R-P(c+a) L-c .
$$

Comparing this to Eq. (3), we obtain the following result:

$\Pi^{C^{*}}-\Pi^{N^{*}}=a$.

In general, $\Pi^{C}$ is less if the utility company cannot verify $c$ (second best case). This is our first explanation of why utility companies may use contracting firms. That is, the utility company uses the contracting firm only if the contracting firm has economies of scale.

\subsection{A Model with Minor Incidents as Motivation for the Use of Contracting Firms}

Next, we introduce the notion of "minor incidents" to suggest another mechanism to explain why the utility company might use the contracting firm even if the contracting firm does not have economies of scale. "Minor incidents" include detection of violations of occupational safety regulations, need for additional operations owing to small difficulties, occurrence of occupational injuries, ${ }^{13}$ and damage to the firm's reputation as a result of those incidents.

Severe accidents are rare at nuclear plants, but minor difficulties are frequent. Table 1 shows the number of reported incidents at nuclear plants run by

\footnotetext{
${ }^{13}$ On May 31, 2011, Ritsuo Hosokawa, the Minister of Health, Labour and Welfare, admitted that ten nuclear plant workers who had leukemia and other cancers related to radiation exposure had been officially acknowledged as having an occupational injury (the smallest radiation exposure was $5.4 \mathrm{mSv}$ ) by the Tohoku Region Pacific Coast Earthquake Reconstruction Special Board of the House of Representatives.
}

Japan's principal utility companies between April 1994 and March 2006. Data are from the website of the Japan Nuclear Technology Institute. During this period, 103 incidents stopped reactor operations. On average, there were 0.18 incidents per reactor per year, and reactors were out of operation 371 hours per incident. Of the 103 incidents, seven reportedly originated in worker error, and the others were caused by facility deterioration such as fatigue, corrosion, and associated consequences.

When minor incidents occur, penalties to the utility company without contracting firms can be larger than those for the utility company with contracting firms because the utility company's reputation is damaged more than the contracting firm's by minor incidents. ${ }^{14}$ Damage to a utility company's reputation raises its costs for nuclear plant operation. For example it makes it difficult and costly to construct new nuclear plants. We show that the utility company's expected profit can be larger by hiring contract workers under this condition. Therefore, we can assume that $L_{M}^{N}>L_{M}^{C}$ where $L_{M}^{C}$ and $L_{M}^{N}$ are losses from minor incidents of the utility company with and without contracting firms, respectively.

The expected profit of the utility company without contracting firms(Eq. [3]) is now replaced by

$$
\Pi^{N}=R-P_{M}(C) L_{M}^{N}-C
$$

where the subscript $M$ indicates minor incidents.

The expected profits of the utility company (Eq. [5]) and contracting firm (Eq. [6]) are replaced by

$$
\begin{aligned}
& \Pi^{C}=R-P_{M}^{C}(F) L_{M}^{C}-\left(1-P_{M}^{C}(F)\right) F \text { and } \\
& \pi=\left(1-p_{M}(c)\right) F-c
\end{aligned}
$$

where the subscript $M$ indicates minor incidents. According to a similar procedure in the case of severe accident, the maximized profits satisfy $\Pi^{C^{*}}>\Pi^{N^{*}}$ if $a=0$, and it is possible that $\Pi^{C^{*}}>\Pi^{N^{*}}$ even if $a<0$. In other words, the utility company may choose to use the contracting firm even if the utility company has economies of scale. Moreover, if the utility company can claim damages for minor incidents from the contracting firms, it is more profitable for the utility company to hire contracting firms than to hire employees. The same result is obtained when we

\footnotetext{
${ }^{14}$ In their case studies, Wells et al. (1991) stated that some plant managers mentioned reputation as a motivation for their use of contract workers.
} 
Table 1: Incidents Causing Reactor Stoppages Between 1994-2005

\begin{tabular}{|c|c|c|c|c|}
\hline Year & Number of incidents & Incidents per reactor & Stop interval & Human error \\
\hline \hline 1994 & 9 & 0.21 & 401 & 1 \\
\hline 1995 & 8 & 0.18 & 170 & 0 \\
\hline 1996 & 7 & 0.16 & 325 & 1 \\
\hline 1997 & 8 & 0.17 & 577 & 279 \\
\hline 1998 & 10 & 0.21 & 120 & 0 \\
\hline 1999 & 8 & 0.17 & 157 & 1 \\
\hline 2000 & 13 & 0.28 & 816 & 0 \\
\hline 2001 & 6 & 0.13 & 95 & 0 \\
\hline 2002 & 3 & 0.06 & 340 & 0 \\
\hline 2003 & 4 & 0.08 & 345 & 1 \\
\hline 2004 & 12 & 0.25 & 601 & 7 \\
\hline 2005 & 15 & 0.31 & 371 & \\
\hline Total & 103 & 0.18 & & \\
\hline
\end{tabular}

Stop interval: (average hours per incident).

Human error: (number of human error-related incidents).

Source: NUCIA, Japan Nuclear Technology Institute.

consider a case in which risk of severe accident and minor incident both exist. The asymmetry of information also allows the utility company to use contracting firms as an excuse for the difficulty of ensuring appropriate safety training, and to avoid both the responsibility and cost of such training. Therefore, it is preferable for the utility company to assign the riskier jobs to contracting firms.

In the above argument, we showed two models that lead us to two testable hypotheses that explain why utility companies use contracting firms in nuclear plants. We test these hypotheses in the next section.

\section{EMPIRICAL ANALYSIS}

In the previous section, we derived two possible hypotheses about a host company's primary motivation for using contract workers. The first is that utility companies use contract workers for temporary work requiring special skills on equipment, and they can enjoy economies of scale by using contracting firms. The second is that utility companies use contract workers to attempt to avoid the responsibilities of being an employer. To examine these hypotheses, we seek evidence through two empirical analyses concerning radiation workers in Japan's nuclear power industry.

\subsection{Empirical Models and Explanatory Variables}

Under the moral hazard model with the economies of scale, the utility company hires the contracting firm only if the contracting firm has economies of scale in temporary jobs requiring specialized worker skills. On the other hand, when damage to the utility company's reputation as a result of minor incidents without the contracting firms is bigger than that with the contracting firms, the utility company may use the contracting firms even if they do not have economies of scale. In the first case, the larger the utility company, the smaller the role of the contracting firms. In the second, the opposite trend is more likely, because the damage becomes more significant as the utility company becomes larger; that is, the incentive to use the contracting firms becomes stronger as the utility company grows larger to avoid damage to its reputation. In this case, a larger host may choose a smaller ratio of employees, since it is expected to demonstrate greater social responsibility and has more of an incentive to avoid embarrassment by failing to do so than smaller firms. Therefore, we can test the hypotheses by evaluating the sign of the coefficient of firm size of the utility company.

We first examine the type of worker preferred by the utility company. Let $r_{i t}^{E}$ be the proportion of utility employees for utility company $i(i=1,2, \ldots, n)$ in year $t$ $(t=1,2, \ldots, T)$ among all radiation workers in the company's plants. The ratio of employees to contract workers is written in the form of an odds ratio,

$$
\frac{r_{i t}^{E}}{1-r_{i t}^{E}}=x_{i t}^{\prime} \beta
$$


where $x_{i t}$ is the vector of explanatory variables, and $\beta$ is the vector of parameters. We ask whether firm size correlates with this variable. The regression is conducted by the minimum chi-square method (in line with Amemiya, 1985, Chapter 9). For the characteristics of the employers, financial data are used. As discussed above, the expected sign of the firm size is negative under the first hypothesis and positive under the second.

Next, we simply examine factors that may affect the probability of a worker being exposed to radiation greater than $5 \mathrm{mSv}^{15}$ We assume that the radiation exposure proxies occupational safety in nuclear plants. We denote the number of workers at utility company $i$ in year $t$ as $n_{i t}$. Let $P_{i j t}$ be the probability of a worker $j$ $\left(j=1,2, \ldots, n_{i t}\right)$ being exposed to radiation $(>5 \mathrm{mSv})$. A logit model of the probability of exposure is represented as

$P_{i j t}=\Lambda\left(z_{i j t}^{\prime} \gamma\right)$

for each of $n_{i t}$ workers, where $z_{i j t}$ is the vector of explanatory variables, $\gamma$ is the vector of parameters, and $\Lambda$ is the cumulative distribution function of the logistic distribution (see, e.g., Amemiya, 1985, Chapter $9)$. As before, the expected sign of the firm size is negative and positive under the first and second hypotheses, respectively.

\subsection{Data}

Numbers for workers exposed to radiation are obtained from the Japan Nuclear Energy Safety Organization (1984 - 2010) for fiscal years 1983 - 2009 (from April through March). The data are available for the nine principal utility companies that operate nuclear plants: Tokyo, Chubu, Kansai, Tohoku, Hokuriku, Chugoku, Shikoku, Kyushu and Hokkaido. (Japan's principal utility companies are named for the regions they serve, and they are practically monopoly local suppliers.) The numbers of contract workers and employees in nuclear plants appear in Figure 3; numbers of contract workers and employees in nuclear plants per reactor are shown in Figure 4. The percentages of contract workers and employees exposed to radiation exceeding $5 \mathrm{mSv}$ were computed from this data. Average values listed for each year

\footnotetext{
${ }^{15}$ Public Notice No. 810 of 1976 , the Ministry of Health, Labour and Welfare stipulates that when a radiation worker has leukemia, his radiation dose, in principle, must not have been less than $0.5 \mathrm{mSv}$ per year for it to be designated as an occupational injury.
}

appear in Figure 5. The number of radiation workers trends upward as the number of nuclear plants increased during this period. The proportion of employees trends upward, while the number of workers per reactor as a whole trends downward. The rate of exposed $(>5 \mathrm{mSv})$ workers trends downward for both employees and contract workers until 1994, and then trends slightly upward. It is necessary to distinguish between the downward effect of technical progress and the upward effect of plant aging. Financial data were obtained from the annual reports of the nine Japanese utility companies that operate nuclear plants. The deflator was obtained from the National Accounts for 2009 (the base year is 2001).

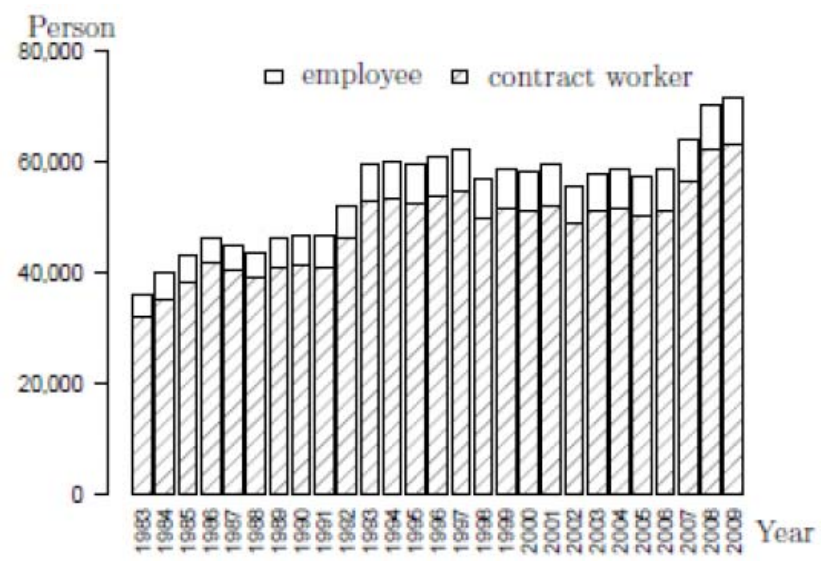

Figure 3: Number of contract workers and employees in nuclear plants (per fiscal year). Source: Japan Nuclear Energy Safety Organization (1984-2010).

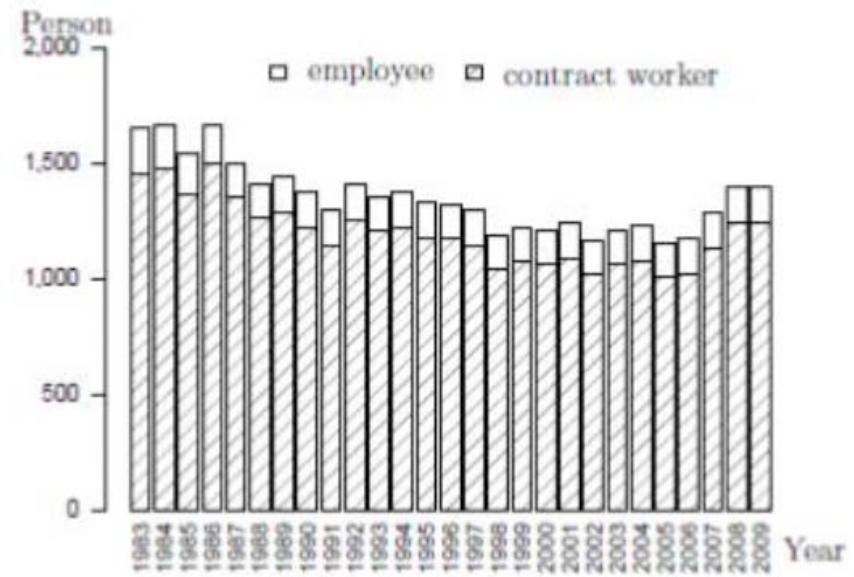

Figure 4: Number of contract workers and employees per reactor in nuclear plants (per fiscal year). Source: Japan Nuclear Energy Safety Organization (1984 - 2010).

The explanatory variables are defined as follows:

C_RATE $\mathrm{it}_{\mathrm{i}}:=$ Number of contract workers/Number of radiation workers, 


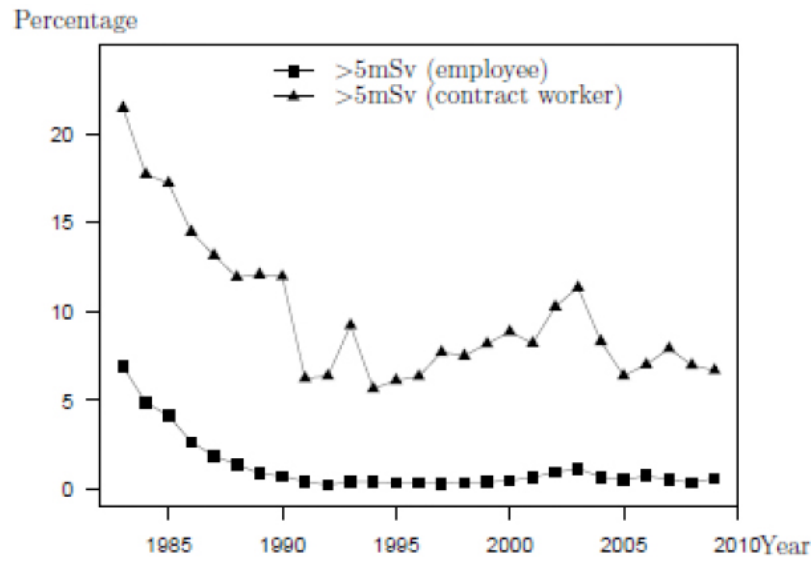

Figure 5: Percentages of contract workers and employees exposed to radiation greater than $5 \mathrm{mSv}$ in nuclear plants (per fiscal year). Source: Japan Nuclear Energy Safety Organization (1984-2010).

\section{F_SIZE $:$ Total size of company's businesses}

$:=$ Average of total ordinary revenues,

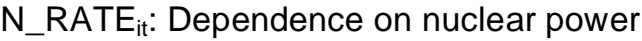

:= Nuclear electricity output/Electricity sales volume,

FEE $_{\text {it }}$ : Contracting firm fee per capita

:= (Repair expenses for nuclear branch+Outsourcing expenses for nuclear branch)/Number of contract workers,

TREND $^{\alpha}$ : Trend $(1984=0)$ powered by a parameter,

$A G E_{i t}:$ Degree of reactor aging

$:=\left(\Sigma_{\text {_ }}\right.$ reactors Accumulated years from beginning of operation)/Number of reactors,

CHANGE $(Y)_{\text {it }}:=1$ if after year $\mathrm{Y}, 0$ otherwise,

C_DUMMY $Y_{\mathrm{ijt}}:=1$ if contract worker, 0 otherwise.

The variables are chosen based on the following considerations:

1. The correlation between $P_{i j t}$ and the ratio of contract workers to all radiation workers is expected to be negatively correlated if the technical advantage of occupational safety is on the contracting firm's side; that is, if contract workers are more highly trained than utility company employees. The correlation tends to be positive if the utility company has the technical advantage.
2. The size of a power utility company, represented by its ordinary revenue, is used to measure the economies of scale in Eq. (14). To exclude temporal fluctuations, we used the average value in the sample period. It is not expected that this variable will be correlated with $P_{i j t}$ if government regulations require a level of safety management that exceeds the plant's optimal level, and the government can verify it. Otherwise, it is expected that the variable will be negatively correlated owing to the utility company's economies of scale. It is expected to be positively correlated with $r_{i t}^{E} /\left(1-r_{i t}^{E}\right)$ if the utility company uses contract workers for temporary jobs requiring some specialization, and negatively correlated if it does so to avoid employer responsibilities.

3. A utility company may invest more in safety management at nuclear plants if it depends extensively on nuclear power. Hence, it is expected that the rate of nuclear power generation will be negatively correlated with $P_{i j t}$.

4. If training costs are reflected in contracting firm fees, the per capita fee of contract workers should also be negatively correlated with $P_{i j t}$. In contrast, if a premium is paid for a lower level of safety (the compensating wage differentials hypothesis), a positive correlation could be expected.

5. The time trend is expected to correlate negatively with $P_{i j t}$, since technical progress and accumulation of experience and knowledge decrease risk. We estimated $a$ in the trend term with a grid search from $(0,1)$ maximizing the likelihood.

6. It is expected that the length of time since the plant commenced operating will be positively correlated with $P_{i j t}$, since old plants generally tend to have more accidents.

7. The structural change dummy should correlate with $P_{i j t}$ if radiation exposure jumped up at some point in time. We determined the breaking point $Y$ from $\{1988, \ldots, 2005\}$ by model selection with AIC.

8. The contract worker dummy should correlate positively with $P_{i j t}$ if contract workers are exposed to more radiation than employees. A positive correlation with $P_{i j t}$ suggests that contract workers are assigned to riskier jobs. 
Table 2: Summary of Variables for Nuclear Power Sections of Utility Companies, 1984- 2010

\begin{tabular}{|c|c|c|c|c|c|c|c|c|c|c|}
\hline $\begin{array}{c}\text { Utility } \\
\text { company }\end{array}$ & & $\begin{array}{c}\text { Total } \\
\text { radiation } \\
\text { workers }\end{array}$ & $\begin{array}{c}\text { Proportion } \\
\text { of } \\
\text { employees } \\
\text { (percent) }\end{array}$ & $\begin{array}{c}\text { Exposed } \\
\text { (employee) } \\
\text { (percent) }\end{array}$ & $\begin{array}{c}\text { Exposed } \\
\text { (contract) } \\
\text { (percent) }\end{array}$ & $\begin{array}{c}\text { Total } \\
\text { revenue } \\
\text { (F_SIZE) }\end{array}$ & $\begin{array}{c}\text { Number } \\
\text { of } \\
\text { reactors }\end{array}$ & AGE & N_RATE & FEE \\
\hline \multirow[t]{4}{*}{ Tokyo } & Mean & 21967 & 9.6 & 2.4 & 11 & 4.72 & 14.4 & 14.1 & 35.3 & 6 \\
\hline & S.D. & 3252 & 1.3 & 3.3 & 5 & 0.52 & 3.1 & 5.8 & 8 & 1.6 \\
\hline & Min. & 14202 & 6.9 & 0.2 & 5.2 & 3.72 & 8 & 6.1 & 14.5 & 3.1 \\
\hline & Max. & 28163 & 12.1 & 14 & 25.9 & 5.68 & 17 & 25.1 & 47.2 & 9.1 \\
\hline \multirow[t]{4}{*}{ Chubu } & Mean & 5143 & 12.6 & 1.9 & 11.8 & 2 & 3.1 & 13.4 & 17.2 & 7.3 \\
\hline & S.D. & 616 & 2 & 2.1 & 5.7 & 0.2 & 0.7 & 4.2 & 4.5 & 2.1 \\
\hline & Min. & 4250 & 9.2 & 0 & 1.3 & 1.64 & 2 & 6.7 & 8.7 & 3.4 \\
\hline & Max. & 6738 & 16.2 & 8.2 & 22.3 & 2.36 & 4 & 19.5 & 24.2 & 11.8 \\
\hline \multirow[t]{4}{*}{ Kansai } & Mean & 11582 & 12.4 & 0.6 & 12 & 2.37 & 10.3 & 17.7 & 45.9 & 9.9 \\
\hline & S.D. & 1281 & 1.1 & 0.6 & 5.4 & 0.19 & 1.2 & 6.8 & 5.2 & 1.5 \\
\hline & Min. & 9720 & 10.4 & 0 & 6.1 & 2.03 & 7 & 8.3 & 36.5 & 6.5 \\
\hline & Max. & 13887 & 14.6 & 2.8 & 24.4 & 2.61 & 11 & 29.7 & 54.6 & 14 \\
\hline \multirow[t]{4}{*}{ Chugoku } & Mean & 2483 & 13.7 & 0.8 & 7.8 & 0.96 & 1.8 & 17 & 15.5 & 6.3 \\
\hline & S.D. & 455 & 2.6 & 2 & 6.5 & 0.08 & 0.4 & 6.3 & 4.5 & 2.2 \\
\hline & Min. & 1798 & 10.5 & 0 & 0.2 & 0.8 & 1 & 7.6 & 8.2 & 2.8 \\
\hline & Max. & 3203 & 19.3 & 10.3 & 26.2 & 1.12 & 2 & 28.6 & 22.7 & 12.1 \\
\hline \multirow[t]{4}{*}{ Hokuriku } & Mean & 2167 & 14.9 & 0.1 & 2.3 & 0.48 & 1.3 & 6.8 & 17.9 & 5.1 \\
\hline & S.D. & 592 & 6.2 & 2 & 2.9 & 0.02 & 0.5 & 3.3 & 8.6 & 3.1 \\
\hline & Min. & 912 & 10.2 & 0 & 0 & 0.44 & 1 & 0.7 & 0 & 1.6 \\
\hline & Max. & 3041 & 31.9 & 0.7 & 11.5 & 0.52 & 2 & 11.7 & 35.6 & 12.2 \\
\hline \multirow[t]{4}{*}{ Tohoku } & Mean & 3136 & 12.9 & 0 & 1.9 & 1.39 & 1.7 & 8.1 & 13.2 & 5.8 \\
\hline & S.D. & 1363 & 2 & 0 & 2.2 & 0.2 & 1.6 & 3.2 & 6.1 & 1.8 \\
\hline & Min. & 1554 & 9.5 & 0 & 0 & 1.05 & 0 & 0.8 & 5.7 & 1.8 \\
\hline & Max. & 6685 & 17 & 0.2 & 9.3 & 1.67 & 4 & 13.3 & 25.8 & 10.4 \\
\hline \multirow[t]{4}{*}{ Shikoku } & Mean & 2514 & 14.1 & 0.5 & 5.7 & 0.49 & 2.6 & 14.3 & 51.6 & 9.9 \\
\hline & S.D. & 455 & 2.5 & 1 & 2.9 & 0.06 & 0.5 & 6 & 7.8 & 2.1 \\
\hline & Min. & 2778 & 9 & 0 & 1.1 & 0.39 & 2 & 4.3 & 35.9 & 5.2 \\
\hline & Max. & 3379 & 17.9 & 3.9 & 10.7 & 0.58 & 3 & 25.3 & 66.1 & 13.9 \\
\hline \multirow[t]{4}{*}{ Kyushu } & Mean & 4984 & 13.5 & 0.4 & 6.5 & 1.28 & 5 & 13 & 43.9 & 10.1 \\
\hline & S.D. & 1285 & 1.6 & 0.4 & 2.1 & 0.14 & 1.2 & 5.7 & 7.6 & 2.6 \\
\hline & Min. & 3161 & 10.3 & 0 & 2.7 & 1.04 & 2 & 4.4 & 21.8 & 3.4 \\
\hline & Max. & 7870 & 16.1 & 1.9 & 10.8 & 1.44 & 6 & 23.7 & 54.3 & 14 \\
\hline \multirow[t]{4}{*}{ Hokkaido } & Mean & 2023 & 15.9 & 0 & 1.3 & 0.52 & 2 & 9.7 & 31.3 & 9.1 \\
\hline & S.D. & 440 & 2.8 & 0 & 1.3 & 0.03 & 0.4 & 5.7 & 5 & 2.8 \\
\hline & Min. & 1507 & 11.5 & 0 & 0 & 0.45 & 1 & 0.8 & 21.3 & 1.9 \\
\hline & Max. & 3261 & 21 & 0 & 4.2 & 0.58 & 3 & 18.9 & 39.4 & 16.1 \\
\hline \multirow[t]{4}{*}{ Total } & Mean & 54629 & 11.6 & 1.2 & 9.8 & 13.86 & 41.3 & 14.2 & 32 & 7.5 \\
\hline & S.D. & 8921 & 0.8 & 1.6 & 4.1 & 1.86 & 9.3 & 5.2 & 4 & 1.4 \\
\hline & Min. & 36207 & 9.9 & 0.2 & 5.7 & 9.81 & 22 & 6.9 & 25.4 & 4.6 \\
\hline & Max. & 71353 & 12.8 & 6.9 & 21.5 & 16.54 & 51 & 23.5 & 39.2 & 9.6 \\
\hline
\end{tabular}

Exposed (Employee): proportion of exposed workers ( $>5 \mathrm{mSv}$ ) among utilities' employees.

Exposed (Contract): proportion of exposed workers ( $>5 \mathrm{mSv}$ ) among contract workers.

Total revenue (F_SIZE): index of firm size (trillion Yen).

AGE: degree of reactor aging.

N_RATE: dependence on nuclear power (percent).

FEE: contractor fee (million Yen)/person.

Source: Japan Nuclear Energy Safety Organization, Operational Status of Nuclear Facilities in Japan (1984-2010).

Cabinet Office, Government of Japan, National Accounts for 2009 (base: 2001). 
Table 2 summarizes the data. On average, 10 - 20 percent of workers are utility employees (the rest are contract workers), and the proportion of exposed workers ( $>5 \mathrm{mSv}$ ) is nearly 10 times higher in contract workers that among employees.

\subsection{Results of Estimation}

Results of our estimations appear in Table 3. The two columns correspond to the two equations described in this section. The first column (Eq. [14]) shows the results of the worker type choice model aimed at revealing why utility companies use contract workers. The second column (Eq. [15]) contains the results of the logit model of exposure probability. The figures are the marginal effects at the average of the utility companies' employees after 1997, except for the two dummy variables CHANGE(1997) and C_DUMMY, which are estimated with C_DUMM $\bar{Y}=1$ and CHANGE(1997) $=1$, respectively. Standard errors are in parentheses. In the results of Eq. (14) (Table 3, column 1 ), the coefficient of F_SIZE is -0.0882 . As mentioned, the negative correlation with $r_{i t}^{E} /\left(1-r_{i t}^{E}\right)$ indicates that the utility company hires contract workers to avoid employer responsibilities. When this fact is considered together with the fact that contract workers receive greater radiation doses than directly hired employees, it is interesting to examine whether utility companies are inclined to contract out risky jobs. The coefficient of N_RATE is -0.285 . This suggests that the more the utility company depends on nuclear power, the more it prefers using contract workers in its nuclear plants. If utility companies recognized that employees were more suitable than contract workers for jobs requiring extensive safety training, this was not reflected in the configuration of the workforce. The coefficient of FEE is 0.0242 , a positive value. This indicates that employees and contract workers are substitutes. The coefficient of TREND is -0.0874 , a negative value, indicating that utility companies were decreasing the proportion of their employees, contrary to the upward trend in Figure 5. The coefficient of AGE is -0.00345 , also a negative value, indicating that companies tended to hire contract workers as their reactors aged. Periodic inspections presumably require more hands for older reactors. The coefficient of CHANGE(1996) is 0.116, indicating that the utility companies increased the ratio of employees to contract workers at this point.

For Eq. (15), the second column of Table 3 reports the marginal effects at the average values of utility companies' employees, where three estimates are significant at the $1 \%$ level. If Eq. (15) is regarded as an equation of occupational safety, the signs of the coefficients of N_RATE, TREND, AGE and C_DUMMY should be negative, negative, positive and positive, respectively. The estimates show that the signs for all
Table 3: Analyses of Radiation Exposure and Worker Type 1983-2009

\begin{tabular}{|c|c|c|}
\hline Model & (1) Odds & (2) $\mathrm{P}(>5 \mathrm{mSv})$ \\
\hline \multirow[t]{2}{*}{ Constant } & $-1.74 \mathrm{E}+00^{* * *}$ & \\
\hline & (1.46E-02) & \\
\hline \multirow[t]{2}{*}{ C_RATE } & & $7.77 \mathrm{E}-02^{* *}$ \\
\hline & & (3.40E-02) \\
\hline \multirow[t]{2}{*}{ F_SIZE } & $-8.82 \mathrm{E}-02^{* * *}$ & $1.38 \mathrm{E}-03$ \\
\hline & (1.89E-03) & (6.09E-02) \\
\hline \multirow[t]{2}{*}{ N_RATE } & $-2.85 \mathrm{E}-01^{* * *}$ & $-1.56 \mathrm{E}-02$ \\
\hline & (2.12E-02) & (1.13E-02) \\
\hline \multirow[t]{2}{*}{ FEE } & $2.42 \mathrm{E}-02^{\star \star *}$ & 1.17E-03 \\
\hline & (1.47E-03) & (2.88E-01) \\
\hline \multirow[t]{2}{*}{ TREND^0.188 } & $-8.74 \mathrm{E}-02^{\star * *}$ & \\
\hline & (9.86E-04) & \\
\hline \multirow[t]{2}{*}{ TREND0.751 } & & $-3.47 \mathrm{E}-03$ \\
\hline & & $(2.53 \mathrm{E}-01)$ \\
\hline \multirow[t]{2}{*}{ AGE } & $-3.45 \mathrm{E}-03^{* * *}$ & 8.19E-04 \\
\hline & (6.19E-04) & (4.79E-01) \\
\hline \multirow[t]{2}{*}{ CHANGE(1996) } & $1.16 \mathrm{E}-01^{* * *}$ & \\
\hline & (7.00E-03) & \\
\hline \multirow[t]{2}{*}{ CHANGE(1997) } & & $4.46 \mathrm{E}-02^{* * *} \mathrm{a}$ \\
\hline & & (3.03E-04) \\
\hline \multirow[t]{2}{*}{ C_DUMMY } & & $7.73 \mathrm{E}-02^{* * *} \mathrm{~b}$ \\
\hline & & (1.73E-03) \\
\hline Observations & 226 & 1474995 \\
\hline LogLikelihood & -1905.57 & -398984 \\
\hline R^2 (sq.corr.) & 0.3757 & \\
\hline McFadden's pR^2 & & 0.06001 \\
\hline
\end{tabular}

First Column: Odds of the proportion of employees.

Number of observations is the total number of firms.

Second Column: Logit of the exposure probability (marginal effect at average). Number of observations is the total.

${ }^{* * *}$ : significant at the 1 percent level.

${ }^{* *}$ : significant at the 5 percent level.

a: Estimated with C_DUMMY=1.

b: Estimated with CHANGE(1997)=1.

Standard errors are in parentheses.

of them are as expected, although the effects of N_RATE, TREND and AGE are not significant at the average values. The marginal effect of C_RATE is 0.0777 , indicating that safety is higher among utility companies that use fewer contract workers in nuclear plants. Two possibilities explain this result. First, contracting firms have technical disadvantages over utility companies when it comes to riskier jobs. Second, contract workers are perhaps less well trained than employees of utility companies. The marginal effect of 
TREND is not significant, indicating that no significant technical progress has reduced the probability of radiation exposure in recent years. The marginal effect of CHANGE(1997) is 0.0446 and significantly positive, while the trend is negative (the coefficient is significant).

Along with the positive coefficient of CHANGE(1996) in Eq. (14), some events might have occurred around this point of time, which increased the probability of radiation exposure and made the utility companies increase the proportion of direct employees in the nuclear plant. Two events might have influenced the utility companies' workforce configuration in nuclear plants. One is an earthquake, the Great Hanshin-Awaji Earthquake Disaster, which occurred on January 7, 1995. The other is an accident that occurred at a fast breeder reactor in Fukui, Japan, on December 8, 1995. This accident focused people's attention on the risk of nuclear plants, even though the reactor was not operated by a utility company, and the accident was rated a level 1 on the International Nuclear Event Scale (INES). This is because it was revealed that the Power Reactor and Nuclear Fuel Development Corporation, the operators of the breeder reactor, falsified reports and edited a videotape of the accident scene before it was broadcast. These events might have forced utility companies to quickly increase radiation workers who were unfamiliar with their jobs. The marginal effect of C_DUMMY is 0.0773 , a positive value. This indicates that the safety level of contract workers is below that of employees. It is possible that the utility company might assign riskier jobs to contracting firms to create informational asymmetry between the regulator and the utility company. Investigating the relationship between safety training and worker type exceeds the scope of this paper.

On the basis of the two models, we obtained two sets of results. First, the utility company hired contracting firms primarily to avoid employer responsibilities. Secondly, the probability of radiation exposure in the nuclear plant was high when the degree of the utility company's dependence on contract workers was high. If we assume that the radiation doses received by workers indicate the lack of occupational safety, it may be effective for regulators to motivate plant operators to replace contract workers with employees they can supervise and instruct. This could be achieved by increasing the cost of using contract workers, and by imposing penalties for running old nuclear plants.

\section{CONCLUSIONS}

When asymmetry of safety-related information occurs between on-site contracting firms and a host company, the level of safety training is assumed to be less than the regulator's requirements because it is more difficult for the regulator to verify the actions of many small contracting firms than those of one utility company. We investigated the laws and regulations governing Japan's nuclear power industry, which uses a sizable number of contract workers and has high safety training costs. The theoretical section examined two types of risks that utility companies account for, and discovered two incentives, economies of scale and avoidance of employer responsibilities, that work in opposite directions as the impetus for using contract workers. The empirical analyses indicated that one primary motivation was that using contract workers allows host plants to circumvent legal responsibilities for safety training. Therefore, regulations and supervision methods by regulators should be revised to maintain the safety and health standards at nuclear power plants.

\section{ACKNOWLEDGEMENTS}

We are grateful to two anonymous referees for their helpful comments. We would also like to thank Professors Kohei Daido, Professor Erin Scott, and Professor Masaru Sasaki. We would also like to thank seminar participants at Kinki University, Waseda University, Hokkaido University, the University of York, Hitotsubashi University, and the University of Tokyo for valuable comments on earlier drafts of the article. This work was supported by the University of Tokyo GCOE program "Nuclear Education and Research Initiative" of the Ministry of Education, Culture, Sports, Science and Technology-Japan, and by a Grant-in-Aid for Scientific Research from the Japan Society of Science and Research (Grant Number 25380264).

\section{REFERENCES}

Abraham, Katharine G., and Susan K. Taylor. 1996. "Firms' Use of Outside Contractors: Theory and Evidence." Journal of Labor Economics 14(3): 394-424. http://dx.doi.org/10.1086/209816

Amuedo-Dorantes, Catalina. 2002. "Work Safety in the Context of Temporary Employment: The Spanish Experience." Industrial and Labor Relations Review 55(2): 262-285. http://dx.doi.org/10.2307/2696208

Amemiya, Takeshi. 1985. Advanced Econometrics. Cambridge: Harvard University Press.

Anayama, Teizo. 2005. Denryoku Sangyo no Keizaigaku (Economics of Electricity Industry). Tokyo: NTT Shuppan (in Japanese). 
Bolton, Patrick, and Mathias Dewatripont. 2005. Contract Theory. Cambridge: The MIT Press.

Cabinet Office, Government of Japan. 2009. National Accounts for 2009. http://www.esri.cao.go.jp/en/sna/data/kakuhou/files/ 2009/tables/21fcm3d_jp.xls (accessed December 13, 2012).

Garen, John. 2006. "Use of Employees and Alternative Work Arrangements in the United States: A Law, Economics, and Organizations Perspective." Labour Economics 13: 107-141. http://dx.doi.org/10.1016/j.labeco.2004.05.003

Grossman, Sanford. J., and Oliver D. Hart. 1986. "The Costs and Benefits of Ownership: A Theory of Vertical and Lateral Integration." Journal of Political Economy 94(4): 691-719. http://dx.doi.org/10.1086/261404

Guadalupe, Maria. 2003. "The Hidden Costs of Fixed Term Contracts: The Impact on Work Accidents." Labour Economics 10: 339-357. http://dx.doi.org/10.1016/S0927-5371(02)00136-7

Hamaguchi, Keiichiro. 2004. Rodoho Seisaku (Law and Policy on Labor). Kyoto: Minerva Shobo (in Japanese).

Hernanz, Virginia, and Luis Toharia. 2006. "Do Temporary Contracts Increase Work Accidents? A Microeconometric Comparison between Italy and Spain." Labour 20(3): 475-504. http://dx.doi.org/10.1111/j.1467-9914.2006.00338.x

Japan Nuclear Energy Safety Organization. 1984-2010. Operational Status of Nuclear Facilities in Japan (in Japanese).

Klein, Benjamin, Robert Crawford, and Armen A. Alchian. 1978. "Vertical Integration, Appropriate Rents, and the Competitive Contracting Process." Journal of Law and Economics 21(2): 297-326. http://dx.doi.org/10.1086/466922

Kochan, Thomas A., Michal Smith, Jhon C. Wells, and James B. Rebitzer. 1992. "Managing the Safety of Contingent Workers: A Study of Contract Workers in the Petrochemical Industry." MIT Sloan School of Management Working Paper 3442-92BPS.

Laffont, Jean-Jacques, and David Martimort. 2002. The Theory of Incentives: The Principal-agent Model. Princeton: Princeton University Press.
Ministry of Health, Labour and Welfare. 2005. The Basic Survey on Industrial Safety and Health (in Japanese).

Japan Nuclear Technology Institute. Nuclear Information Archives. http://www.nucia.jp (accessed December 22, 2010).

OECD. OECD Indicators of Employment Protection. http://www. oecd.org/employment/protection (accessed April 26, 2010).

Rebitzer, James B. 1995. "Job Safety and Contract Workers in the Petrochemical Industry." Industrial Relations 34(1): 40-57. http://dx.doi.org/10.1111/j.1468-232X.1995.tb00359.x

Rothschild, Michael., and Joseph E. Stiglitz. 1976. "Equilibrium in Competitive Insurance Markets: An Essay on the Economics of Imperfect Information." The Quarterly Journal of Economics 90(4): 629-649. http://dx.doi.org/10.2307/1885326

Shimizu, Shuji. 2002. "Paburikku Akuseputansu no Seiji Shakairon (2) (On the Public Acceptance of Nuclear Power Facilities (2))." The Shogaku Ronshu (Journal of Commerce, Economics and Economic History) 70(4): 143-160 (in Japanese).

Shirai, Kunihiko. 2007. "Gyomu Ukeoi to Rodo Mondai (Contract Job and Labor Problem)." Nihon Rodo Nenkan (The Labour Year Book of Japan), 77: Ohara Shakai Mondai Kenkyujo (in Japanese).

Sugeno, Kazuo. 1992. Japanese Labor Law. Seattle: University of Washington Press.

Uezu, Yasuhiro, Takeshi Ouchi, Kenji Shirai, and Yoshibumi Terakado. 2007. "Nihon Genshiryoku Kenkyuu Kaihatsu Kikou ni okeru Roudou Saigai Toukei (The Industrial Accident Statistics in JAEA)." Paper presented at Atomic Energy Society of Japan 2007 Fall Meeting of AESJ, Kitakyushu International Conference Center, Fukuoka, Japan.

Wells, John C., Thomas A. Kochan, and Michal Smith. 1991. Managing Workplace Safety and Health: The Case of Contract Labor in the U.S. Petrochemical Industry. 3 vols. The John Gray Institute, Lamer University.

Williamson, Oliver E. 1971. "The Vertical Integration of Production: Market Failure Consideration." American Economic Review 61(1), 112-123.

Received on 15-10-2014

Accepted on 06-11-2014

Published on 05-12-2014

DOI: http://dx.doi.org/10.6000/1929-7092.2014.03.31

(C) 2014 Matsumoto et al.; Licensee Lifescience Global.

This is an open access article licensed under the terms of the Creative Commons Attribution Non-Commercial License (http://creativecommons.org/licenses/by-nc/3.0/) which permits unrestricted, non-commercial use, distribution and reproduction in any medium, provided the work is properly cited. 